\title{
Effects of Length to the Diameter Ratio on the Buckling Behavior of Cylinders under Axial Load
}

\author{
Ahmed Farhan Kadhum \\ Building and Construction Eng. Depart. \\ University of Technology, Baghdad- IRAQ \\ ahmedms1976@yahoo.co.uk \\ Received: 27-08-2017 \\ Revised: 23-10-2017 Accepted: 18-Dec.-2017 \\ http://doi.org/10.29194/NJES21020187
}

\begin{abstract}
In this research the behavior of cylindrical shells under axial load have been studied. The experimental program is included two groups: the first consists of nine cylinders; each has a diameter of $150 \mathrm{~mm}$, while the height varies from 100 to $500 \mathrm{~mm}$ and thickness of $1.5 \mathrm{~mm}$, test results show that the optimum height to achieve the maximum strength is $300 \mathrm{~mm}$ with $\mathrm{L} / \mathrm{D}$ equal to 2 . The second group consists of two cylinders with diameter of $150 \mathrm{~mm}$ and height of 300 and $500 \mathrm{~mm}$ strengthened with stiffeners plate welding from inside at four quarters with thickness of $1.5 \mathrm{~mm}$ and width $20 \mathrm{~mm}$ fabricated from the same metal of the cylinders. After testing these two cylinders were gain an increase in the strength reached to $42 \%$ for $300 \mathrm{~mm}$ cylinder and $26.4 \%$ for $500 \mathrm{~mm}$ cylinder. The failure modes for these two groups are: the buckling at bottom like "elephant's foot" for cylinders height from 100 to $300 \mathrm{~mm}$ and "inelastic buckling" for cylinders height from 350 to $500 \mathrm{~mm}$ for the first group, and the " inelastic buckling” for the second group.
\end{abstract}

Keywords: Cylinders, L/D, Buckling, Elephant's foot, Inelastic buckling.

\section{Introduction}

The cylindrical shell structures are generally high efficient structures; they have wide applications in the field of mechanical, civil, aerospace, marine, power plants etc. In general, if the thickness of the wall of a shell is less than $1 / 10^{\text {th }}$ to $1 / 15^{\text {th }}$ of its diameter, it is known as a thin shell, Khurmi, R. S., [1].

Modern structures are designed for the most part as those that are assembled with the combined use of thin shells and slender members to contradictory requirements of reduced weight and high strength.

One of the important applications in civil engineering is the thin cylindrical shell buckling strength, Minjie et al., [2], under uniform load experimental and theoretical observations record which show a significant stress non-uniformity, hence a deviation from the buckling strength and explore under localized axial compression a typical thin cylindrical silo. So identify two different buckling phenomena, also a geometric imperfection influence is also considered on the buckling strength.

There are two types of buckling take place in the very thin shell: primary buckling which is called elastic buckling and secondary buckling which is lead to a significant reduction in the number of the circumferential waves, Kobayashi and Mihara, [3].

A simulation is achieved, Prabu et al., [4], using a finite element method to model different sizes of circular dent at half the height of cylindrical shells, the parameter of this analysis is "external of dent present over an area". The ANSYS finite element program used in this simulation, the extent of dent present over an area is more influence than dent depth. This conclusion is verified by finite element models of two circular dents at half of cylindrical shell placed $180^{\circ}$ apart with different dent sizes.

Experimental and numerical investigation are achieved, Kabir and Nazari, [5], of circular cylinders behavior under compression with certain size ratio and various configuration of notch. To evaluate the ultimate strength of these cylinders the researchers use ABAQUS software with nonlinear finite element. A compare between the numerical and observed experiments is happened, the results of these comparison is that the nonlinear analysis results is more accurate than the linear analysis, further a consideration take into account: repairing purposes of deformed shape and stress distribution of the critical region.

The influence of section slenderness on the inelastic and elastic bending properties also, the influence of stiffeners welded in the steel tube of thin-walled CHS studied, Guo et al., [6], as a series include sixteen bending test. These tubes were tested to failure which have diameter to thickness ratio (D/t) varying from 75 to 300 . From the experimental results it concluded that the specimens with small diameter to thickness ratios failed by extensive plastification at the center while, failure become local buckling with increase 
of diameter to thickness. The local carrying capacity increase and the ductility improve with the existence of stiffeners.

The buckling strength of thin cylindrical shells under uniform and non-uniform compressive loads analyzed, Elso, [7], the parameters of this work is the stability of cylinder shells with thinwalled, and with different combinations of loads. The deformation of a cylindrical shell affect by the external loads variable.

By using the finite element program ABAQUS using dynamic, steel tubular wind turbine towers analyzed, $\mathrm{Hu} \mathrm{Y}$. et al., [8], these towers with height varies from 50 to $250 \mathrm{~m}$ are considered and investigated. Three different design options are taken into account in the analysis: 1-thick wall with stiffening rings, 2- thick wall without stiffening rings, and 3- thin wall with stiffening. The parameters of this analysis are: weight reduction ratios in reduction to the horizontal sway and the ratio of Von Misses stress increase to identify the design approach effect.

\section{Mechanical properties of test cylinder}

The cylinders were fabricated from Cobalt Iron alloy Co3Fe7. The material properties for this alloy were determined by worked tensile coupon test which was paint with white color as shown in Fig. 1-a. This tensile coupon was carried out and tested according to the Annual Book of ASTM (ASTM 2009) [9] by using Universal Test Machine with friction grips in the Production and Metallurgy Engineering Department laboratory at the University of Technology as shown in Fig. 1b. The material properties are shown in Fig. 2 and Table 1.

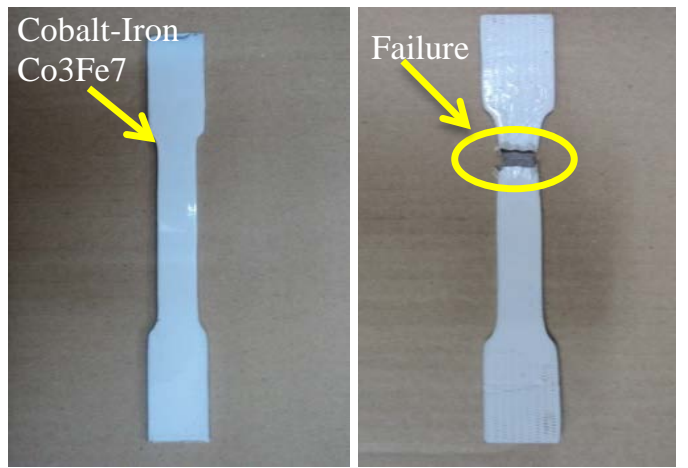

(a) Test specimen before and after testing.

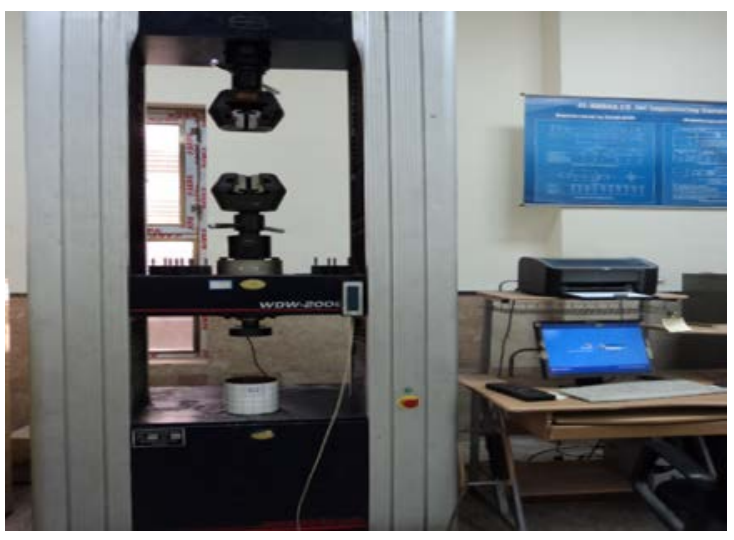

(b) Material testing machine.

Figure 1: Test specimen and testing machine used in this research.

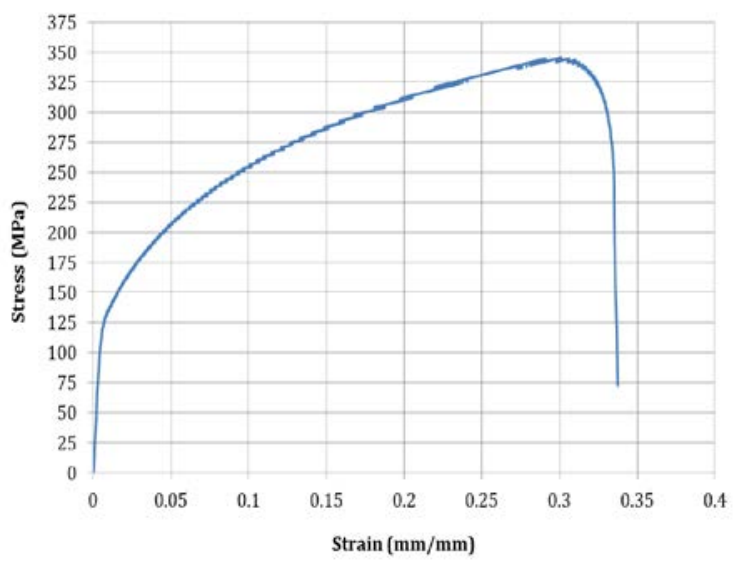

Figure 2: Tensile test curve for cylinder.

Table 1: Material properties for cylinder.

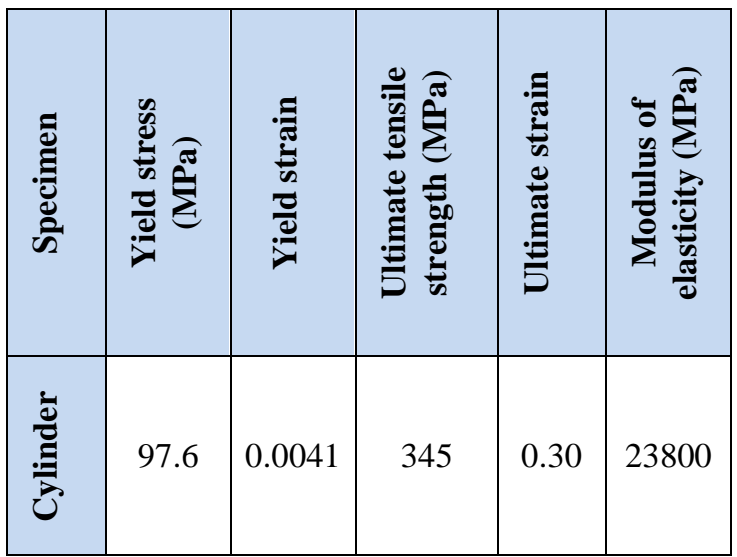

\section{Experimental work}

The experimental program of this research is consisting of two groups:

- Group A: consists of nine cylinders denoted by $\mathrm{C} 1$ to $\mathrm{C} 9$ as shown in Fig. 3 and listed in Table 2. 
- Group B: this group consists of two cylinders denoted by CS4 and CS9 stiffened by plate stiffeners welded from inside at four quarters with $1.5 \mathrm{~mm}$ thickness and $20 \mathrm{~mm}$ width, this stiffeners made from the same material plate of the cylinders as listed in Table 2 and shown in Fig. 4.

These cylinders were set up from alloy metal sheet cut to the proper size by using a metal cutting machine and then rolled by rolling machine to take the cylindrical shape and welded by using the type E6013 electrodes through the height of the cylinder and paint with white color and meshed with blue lines as shown in Figs. 3 and 4.

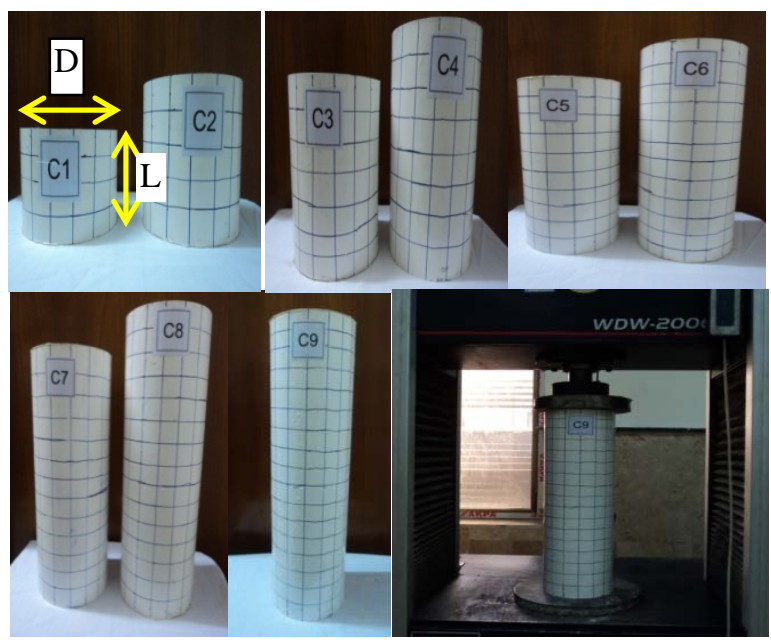

Figure 3: Cylinder specimens C1 to C9.

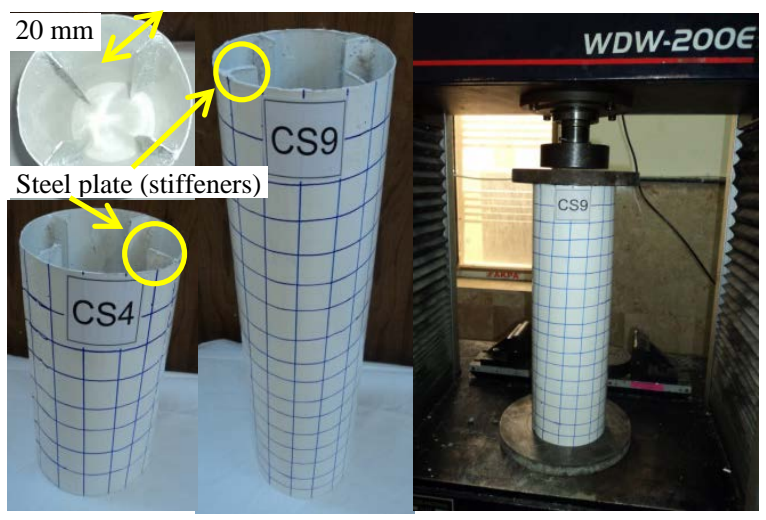

Figure 4: Cylinder specimens CS4 and CS9.

Table 2: Description of test specimens.

\begin{tabular}{|c|c|c|c|c|}
\hline 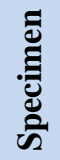 & 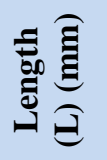 & 冚 & 总 & $\underset{\Xi}{\ominus}$ \\
\hline C1 & 100 & 150 & 1.5 & 0.67 \\
\hline C2 & 150 & 150 & 1.5 & 1.00 \\
\hline C3 & 200 & 150 & 1.5 & 1.33 \\
\hline C4 & 250 & 150 & 1.5 & 1.66 \\
\hline C5 & 300 & 150 & 1.5 & 2.00 \\
\hline
\end{tabular}

\begin{tabular}{|l|l|l|l|l|}
\hline C6 & 350 & 150 & 1.5 & 2.33 \\
\hline C7 & 400 & 150 & 1.5 & 2.66 \\
\hline C8 & 450 & 150 & 1.5 & 3.00 \\
\hline C9 & 500 & 150 & 1.5 & 3.33 \\
\hline CS4 & 300 & 150 & 1.5 & 2.00 \\
\hline CS9 & 500 & 150 & 1.5 & 3.33 \\
\hline
\end{tabular}

\section{Test results}

All the cylinders were tested under compression load applied by Universal Testing Machine, as shown in Fig. 5 below. For supporting these cylinders were located between two thick steel plates, while the applied load was entered into the cylinders through the top plate. These two thick circular steel plates were arranged to support the cylinder specimens under the applied load during the test, one of them was placed at the bottom which works as a base to the cylinders, the other one was placed at the top of the specimens to transform the load from the testing machine and distribute it on the circular edges of the specimens as shown in Fig. 5.

The strength of the cylinders from C1 to C5 is increase as shown in Figs. 6 to 10 while the strength of the cylinders from C6 to C9 decrease as shown in Figs. 11 to 14 and summarized in Table 3.

The cylinders from $\mathrm{C} 1$ to $\mathrm{C} 4$ that have height equal and less than $300 \mathrm{~mm}$ were failed by mode of buckling at bottom end which is called an "elephant's foot buckling: a high level of internal pressurization occurs in the cylinder, even very thin cylinders yields before buckling, where the circumferential membrane and the bending stresses are amplified by the axial compression" [10], as shown in Figs 6 to 9. The cylinders from C5 to C9 were failed by buckling at top end which have height from 350 to $500 \mathrm{~mm}$ as shown in Figs. 10 to 14 . The values of cylinders' failure load for C1 to C9 are summarized in table 3, while the load vs. deflection curves for these cylinders are shown in Figs. 6 to 14.

The cylinders C4 and C9 were strengthened from inside by stiffener plates and designated by CS4 and CS9 as shown in Fig. 4 above. The strength of these two cylinders is increase as shown in Figs. 15 and 16 and summarized in Table 3.

The buckling mode failure of CS4 cylinder was at the bottom with two waves "it is a cylindrical buckle extended over the entire surface" [11], as shown in Fig. 15, while cylinder CS9 failed by "Inelastic buckling: a portion of the cross-section has yielded and the failure occurs by buckling [12], when some of the fibers will reach the yield stress and some will not. The member will fail by both yielding and buckling, and their behavior is said to be inelastic this column is called intermediate column [13]” at the upper 
middle with one wave as shown in Fig. 16. The values of cylinders failure load for CS4 and CS9 are summarized in table 3 , while the load vs. deflection curves for these two cylinders are shown in Figs. 15 and 16. Figure 17 shows the load vs. deflection curves for the whole tested cylinders.

\section{Discussion of test results}

1. The strength of the cylinders $\mathrm{C} 1$ to $\mathrm{C} 5$ were increase with cylinders height increase from 100 to $300 \mathrm{~mm}$ with $\mathrm{L} / \mathrm{D}$ ratio reach to 2 as summarized in table 2 above, because the cylinder shape geometry that resist buckling has $\mathrm{n}=2$ "sine curve shape", in other word " $a$ column whose length is less than Ly (Limit Yield Load) would fail by yielding and could be called a short column, whereas a column with a length greater than Ly would fail by buckling and be called a long column" [14], and "the stress at which a column buckles decrease as the column becomes longer. After it reaches a certain length, that stress will have fallen to the proportional limit of the steel. For that length and greater lengths, the buckling stress will be elastic" [13].

2. Increasing cylinders height from $\mathrm{C} 1$ to $\mathrm{C} 5$ lead to increase in the strength by about $20.3 \%$ because the increase in the metal intensity because the height, while when the height of cylinders increase from C6 to C9 there is decrease in the strength by about $11.8 \%$ because the inelastic buckling.

3. It can be notice that the cylinders from $\mathrm{C} 1$ to C4 as shown in Figs. 6 to 9 were buckling at the bottom as an (elephant's foot) mode, while the cylinders from C5 to C9 as shown in Figs. 10 to 14 their buckling occurred at the top with two modes like: (Inelastic Buckling) For cylinders C5, C6 and C7 and an (elephant's foot buckling) for C8 and C9 cylinders.

The reason for this behavior is that: the cylinders from C1 to C4 their stresses can transmission from top where the load is applied along the cylinders to the base because these cylinders have L/D less than 2, while the cylinders from C5 to C9 which have L/D ratio equal to 2 and more their stresses are still cumulative at the top without moving down to the base because the long transmission path of these stresses "To every action there is an equal and opposite reaction” [Newton's third law].

4. Because of the applied external forces which distributed uniformly at the edge of cylinders with maximum radial stresses, and since these edges free to move in the tangential direction; the phenomenon which is called bifurcation take place and lead to yield these edges then the cylinders were fail. In this study this phenomenon occurred at distance $30 \mathrm{~mm}$ from the edges.

5. The buckling happened as a circumferential wave to the outside and around the cylinder, either at the bottom end such as the Cylinders $\mathrm{C} 1, \mathrm{C} 2, \mathrm{C} 3$ and $\mathrm{C} 4$ or at the top end such as the cylinders C5, C6, C7, C8, and C9. When the buckling is more aggressive in the cylinder the curve of load vs. deflection change from smooth top to sharp top and can be notice sudden drop in this curve because the inelastic buckling as shown in Figs. 10 to 12.

6. The strength of stiffened cylinders CS4 and CS9 increase by about $42 \%$ and $26.4 \%$ respectively as shown in Figs. 15 and 16 of load vs. deflection curve and summarized in table 3 . The cylinder CS4 failed by buckling at the bottom with two waves $n=2$ while the cylinder CS9 failed by inelastic buckling at the upper middle part of the cylinder as shown in Figs. 15 and 16.

7. The percentage of difference between the yield compression strength to the ultimate compression strength of steel cylinders as listed in (table 4 - column 3), increase from $12.3 \%$ for cylinder C1 to $28.6 \%$ for cylinder C5 because the failure by (elephant's foot buckling), while for cylinders C6 to C9 this percentage decrease from $22.3 \%$ to $20.5 \%$ respectively because the failure by (Inelastic buckling).

8. For cylinders CS4 and CS9 which strengthened with plate stiffeners this deference become zero as listed in (table 4 column 3), which means the compatibility between yield and ultimate point, because of sudden buckling without passing through the yield stage.

9. For tensile to compression yield ratio the percentage increase from $41.3 \%$ for cylinder C1 to $59.4 \%$ for cylinder C8 as listed in (table 4 -column 4), because the cylindrical shape of these shell metal, for CS4 and CS9 cylinders these ratio increase obviously to reach about $148.8 \%$ and $116.1 \%$ respectively.

10. while for tensile to compression ultimate ratio this percentage decrease from $55.1 \%$ for cylinder C1 to $46.0 \%$ for cylinder C5 and then increase from $47.6 \%$ for cylinder C6 to $51.6 \%$ for cylinder $\mathrm{C} 9$, while this percentage decrease to $29.6 \%$ for cylinder CS4 and $38.6 \%$ for cylinder CS9 as listed in (table 4 - column 4), because the steel is much stronger in tension than compression. 


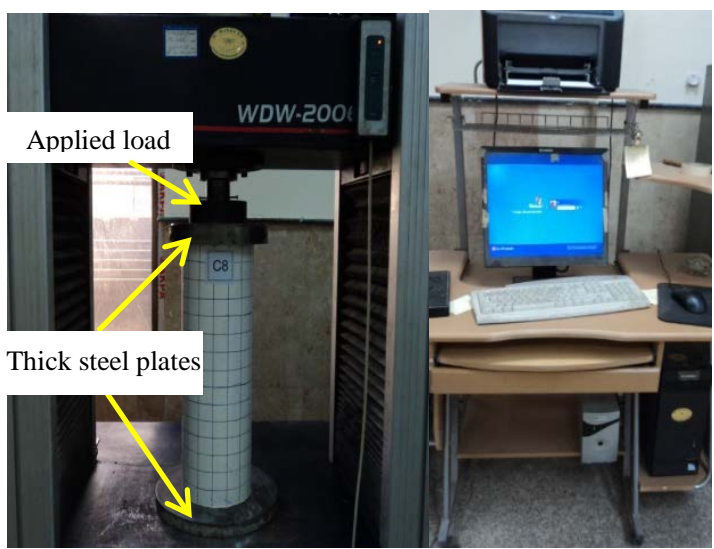

(a) Main frame

(b) Computer control unite

Figure 5: Electronic Universal Testing Machine

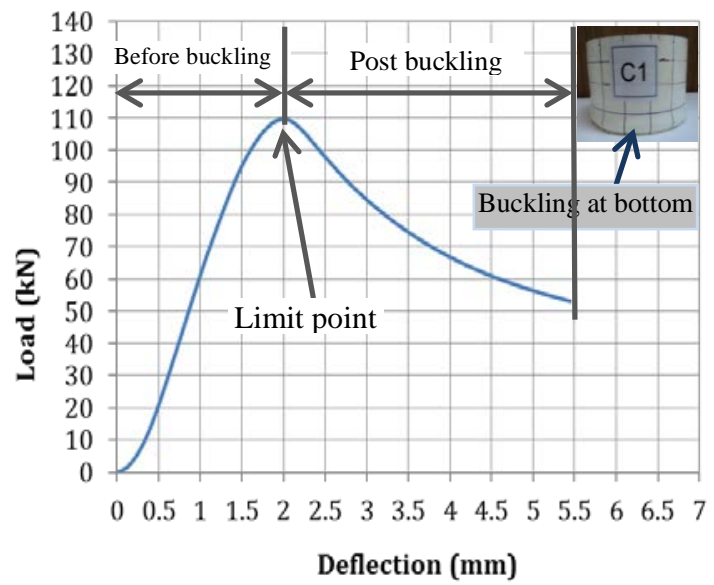

Figure. 6: Load-Deflection curve for cylinder (C1)

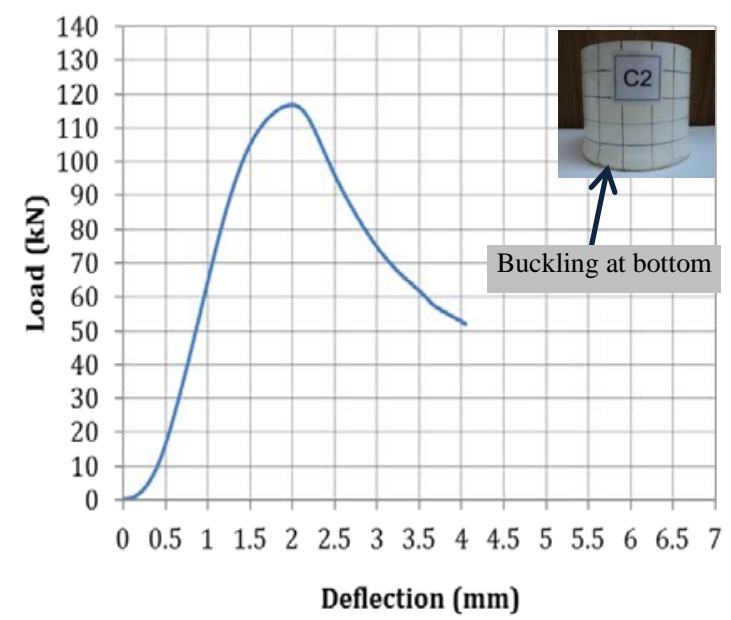

Figure 7: Load-Deflection curve for cylinder (C2)

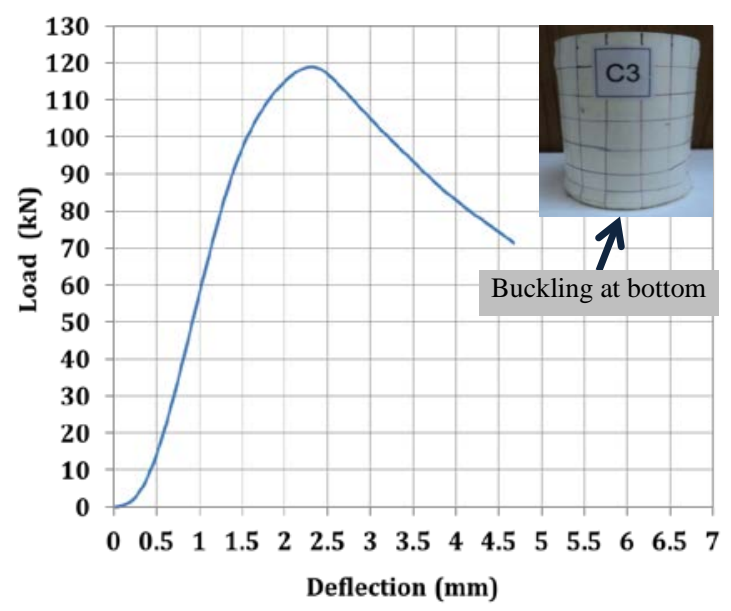

Figure 8: Load-Deflection curve for cylinder (C3)

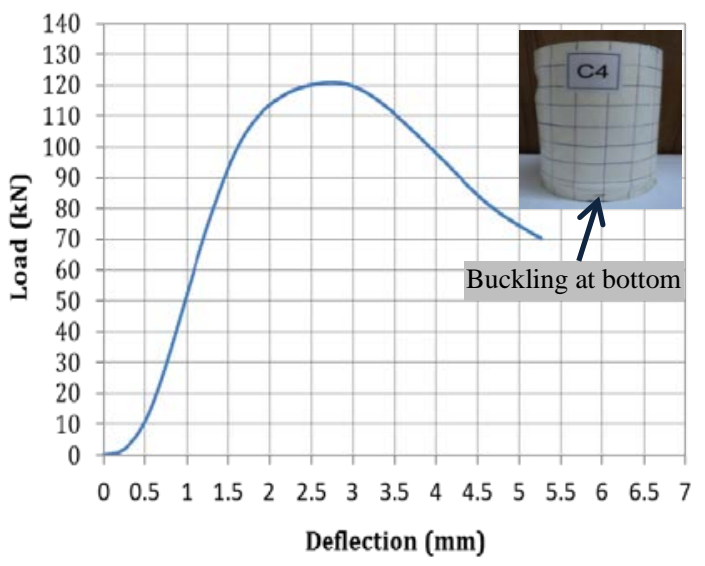

Figure 9: Load-Deflection curve for cylinder (C4)

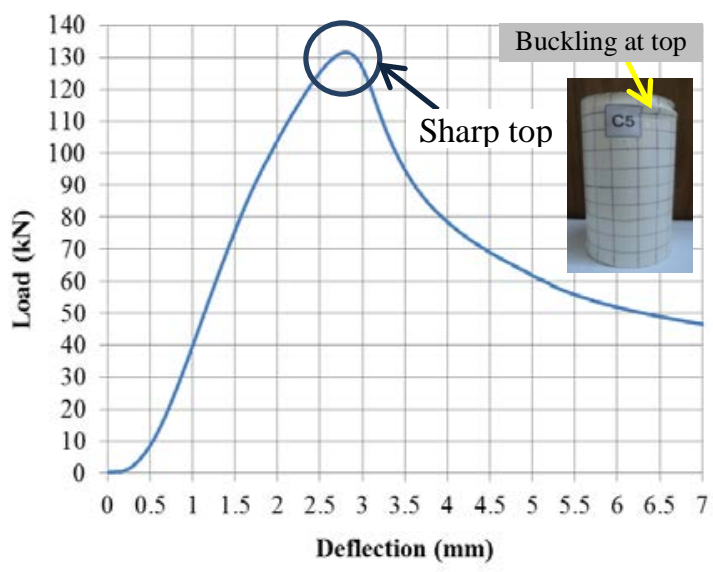

Figure 10: Load-Deflection curve for cylinder (C5) 


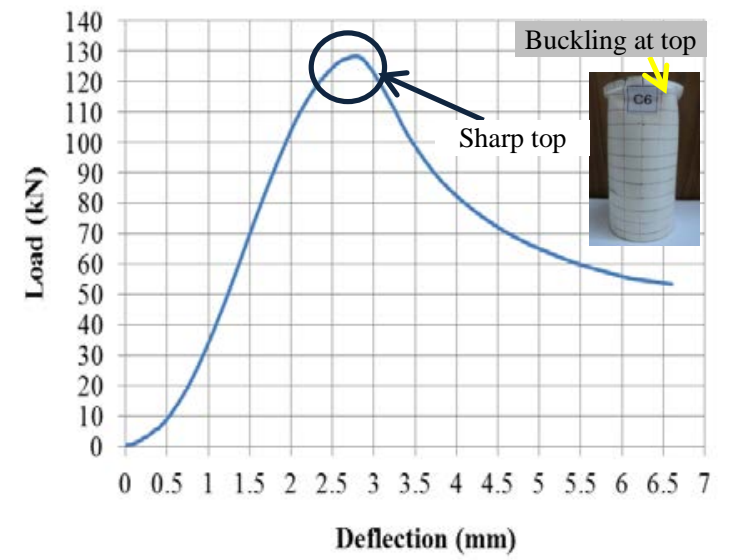

Figure 11: Load-Deflection curve for cylinder (C6)

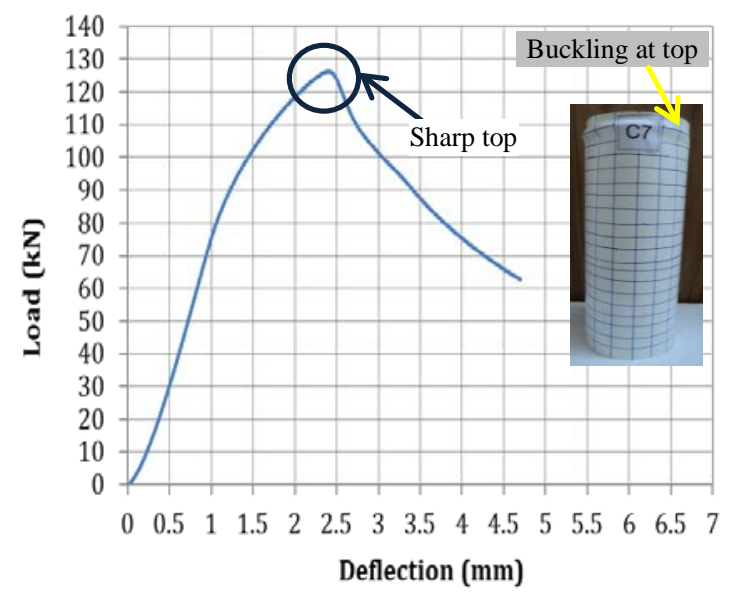

Figure 12: Load-Deflection curve for cylinder (C7)

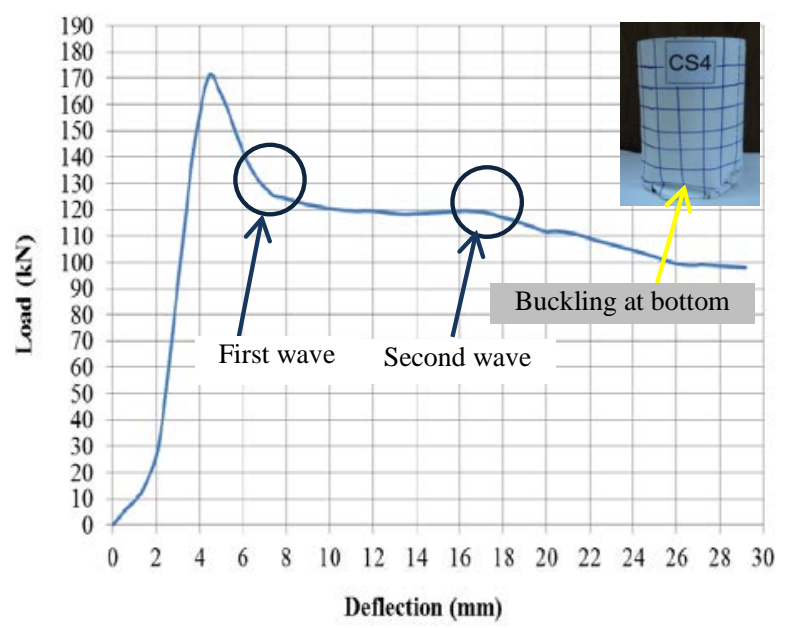

Figure 15: Load-Deflection curve for cylinder (CS4)

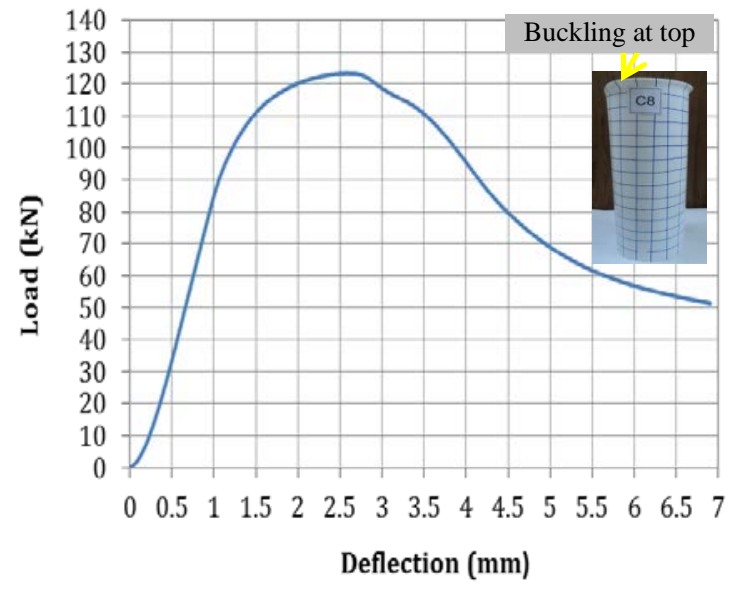

Figure 13: Load-Deflection curve for cylinder (C8)

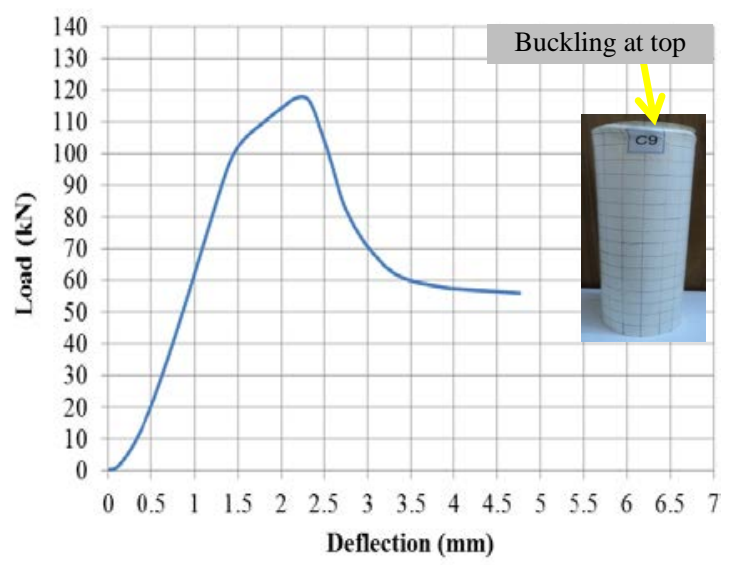

Figure 14: Load-Deflection curve for cylinder (C9)

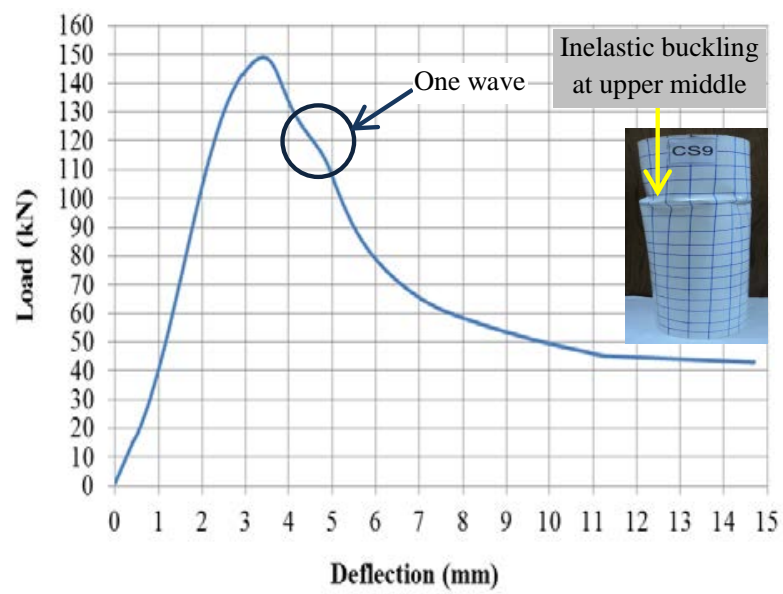

Figure 16: Load-Deflection curve for cylinder (CS9) 


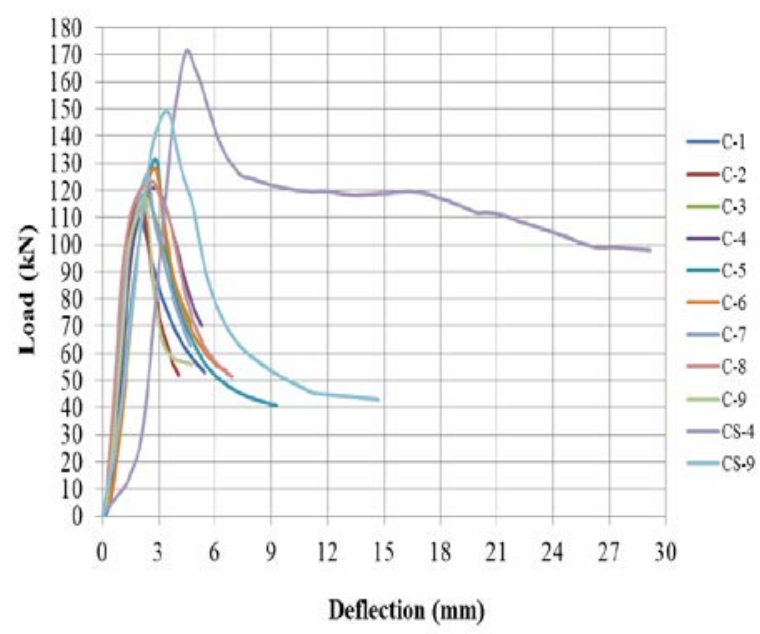

Figure 17: Load-Deflection curves for cylinders

Table 3: Test results and type failure of cylinders.

\begin{tabular}{|c|c|c|c|}
\hline & But & \\
\hline C1 & 109.56 & 2.0162 & Buckling at bottom end \\
\hline C2 & 116.00 & 2.0037 & Buckling at bottom end \\
\hline C3 & 118.98 & 2.3325 & Buckling at bottom end \\
\hline C4 & 120.80 & 2.7575 & Buckling at bottom end \\
\hline C5 & 131.84 & 3.8212 & Buckling at top end \\
\hline C6 & 128.38 & 3.285 & Buckling at top end \\
\hline C7 & 126.32 & 2.4 & Buckling at top end \\
\hline C8 & 123.40 & 2.6163 & Buckling at top end \\
\hline C9 & 117.92 & 3.07 & Buckling at top end \\
\hline CS4 & 171.64 & 6.5075 & Buckling at bottom end \\
\hline CS9 & 149.08 & 6.3337 & $\begin{array}{c}\text { Inelastic buckling at } \\
\text { upper middle }\end{array}$ \\
\hline
\end{tabular}

Table 4: Comparison between tensile test and compression applied load of steel cylinders.

\begin{tabular}{|c|c|c|c|c|c|c|c|}
\hline $\begin{array}{l}\text { ¿्: } \\
\text {. } \\
\text { के }\end{array}$ & 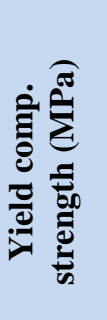 & 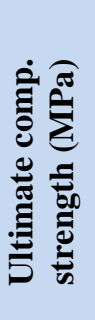 & 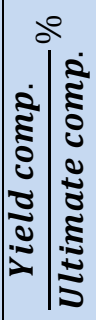 & 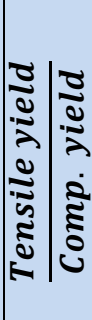 & 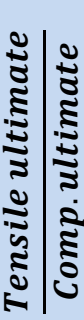 & 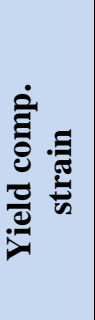 & 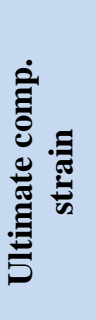 \\
\hline C1 & 138.0 & 155.0 & 12.3 & 41.3 & 55.1 & 0.015 & 0.020 \\
\hline C2 & 140.7 & 164.1 & 16.6 & 44.2 & 52.4 & 0.009 & 0.013 \\
\hline C3 & 141.5 & 168.3 & 18.9 & 45.1 & 51.2 & 0.008 & 0.011 \\
\hline C4 & 142.8 & 170.8 & 19.6 & 46.4 & 50.5 & 0.006 & 0.011 \\
\hline C5 & 145.0 & 186.5 & 28.6 & 48.6 & 46.0 & 0.009 & 0.012 \\
\hline C6 & 148.5 & 181.6 & 22.3 & 52.2 & 47.4 & 0.008 & 0.009 \\
\hline C7 & 150.0 & 178.7 & 19.1 & 53.7 & 48.2 & 0.004 & 0.006 \\
\hline C8 & 155.6 & 174.5 & 12.2 & 59.4 & 49.4 & 0.003 & 0.006 \\
\hline
\end{tabular}

\begin{tabular}{|c|c|c|c|c|c|c|c|}
\hline C9 & 138.3 & 166.8 & 20.5 & 41.8 & 51.6 & 0.004 & 0.006 \\
\hline CS4 & 242.8 & 242.8 & 00 & 148.8 & 29.6 & 0.021 & 0.021 \\
\hline CS9 & 210.9 & 210.9 & 00 & 116.1 & 38.9 & 0.013 & 0.013 \\
\hline
\end{tabular}

* Yield stress of tensile test 97.6 MPa;

**Ultimate strength tensile test 345MPa.

\section{Conclusions}

From the test results of the experimental can be concluded that:

1. The increase in the ratio of $\mathrm{L} / \mathrm{D}$ to a certain value equal to 2 increase the strength by about $20.3 \%$ and the mode of failure cylinders were buckling as an "elephant's foot" at the bottom.

2. When the $L / D$ ratio is increase more than 2 the strength of the cylinders decrease by about $11.8 \%$ because the inelastic buckling of these cylinders.

3. The strength of the other two stiffened cylinders is increase by about $42 \%$ and $26.4 \%$ which have L/D 2 and 3.33 respectively. The failure types of these two cylinders are buckling at the bottom for the first one and inelastic buckling at the upper middle part for the second.

4. The percentage of yield to ultimate compression strength of the cylinders increase from $12.3 \%$ to $28.6 \%$ because the elephant's foot buckling failure while this percentage decrease to $20.5 \%$ because the inelastic buckling failure and this percentage is zero when the cylinders failed by sudden buckling .

5. The tensile to compression yield ratio increase from $41.3 \%$ to $59.4 \%$ and for stiffened cylinders these ratio increase to $148.8 \%$, while for tensile to compression ultimate ration decrease from $55.1 \%$ to $46.0 \%$ and for stiffened cylinders $29.6 \%$ because the steel is much stronger in tension than compression respectively at the ultimate than yield.

\section{References}

1. Khurmi, R. S., 2010, "Strength of Materials (Mechanics of Solids)”, S. Chand \& Company Ltd, Ram Nagar, New Delhi, 843 pp.

2. Cai Minjie, Holst J. M. F. G. and Rotter J. M., 2002, "Buckling Strength of Thin Cylindrical Shells Under Localized Axial Compression”, $15^{\text {th }}$ ASCE Engineering Mechanics Conference, Columbia University, New York, pp. 1-8 <http://www.reserchgate.net /publication/ 228422260>.

3. Kobayashi T. and Mihara Y., 2009, "Post Buckling Analysis of Elastic Cylindrical Shells Under Axial Compression”, SIMULIA, Customer Conference, pp. 115<http://www.simulia.com>. 
4. Prabu B., Raviprakash A.V. and Rathinam N., 2010, "Parametric Study on Buckling Behavior of Thin Stainless Steel Cylindrical Shells for Circular Dent Dimensional Variations under Uniform Axial Compression", International Journal of Engineering Science and Technology Vol. 2, No. 4, pp. 134-149.

5. Kabir, M. Z., and Nazari, A., 2012, "Experimental and Numerical Study on The Nonlinear Response of Notched Cylinders under Compressive Loading”, Scientia Iranica Transaction A: Civil Engineering, Vol. 19, No. 3, pp. 355-365, www.sciencedirect.com.

6. Guo L., Yang S. and Jiao H., 2013, "Behavior of Thin-Walled Circular Hollow Section Tubes Subjected to Bending”, Elsiver, Thin Walled Structures, Vol. 73, pp. 281-289, www.elsiver.com/locate.tws.

7. Elso M. I., 2012, "Finite Element Method Studies on The Stability Behavior of Cylindrical Shells Under Axial and Radial Uniform and Non-Uniform Loads”, Department of Mechanical and Process Engineering Hochschule Niederrhein, University of Applied Sciences, Duechland, 88 pp., www.academica-eunavarra.es.

8. Hu Y., Baniotopoulos C., Yang J., 2014, "Effect of internal stiffening rings and wall thickness on the structural response of steel wind turbine towers”, Elsevier, Engineering structures, Vol. 81, pp.148-161, www.elsevier.com.

9. American Society for Testing and Materials (ASTM) "2009 Annual Book of ASTM Standards”, Vol. 3.01 Standard Test Methods of Tension Testing of Metallic Materials, Pennsylvania, USA, 2009.

10. Rotter J. M., 2006, “Elephant’s Foot Buckling in Pressurised Cylindrical Shells”, Stahlbau, Vol. 75, Heft 9, pp. 742-747.

11. Esslinger M., Ciprian J., 1982, "Buckling of Thin Conical Shells under Axial Loads with and Without Internal Pressure”, In: Buckling of Shells: Proceedings of a State-of-the-Art Colloquium (ed. Ramm E), Berlin: SpringerVerlag., pp.355-374.

12. Salmon G., Johnson E, and Malhas A., 2009, "Steel Structures Design and Behavior, Emphasizing Load and Resistance Factor Design”, United States of America, Pearson Education International, Fifth Edition, 884 pp.

13. McCormac C., and Csernak F., 2013, "Structural Steel Design" $5^{\text {th }}$ Edition, Pearson Education Limited, Indian Edition Published by Dorling Kinderseley Indian Pvt., 736 pp.

14.Geschwindner F., 2008, "Unified Design of Steel Structures”, United States of America, John Wiley \& Sons, 444 pp.
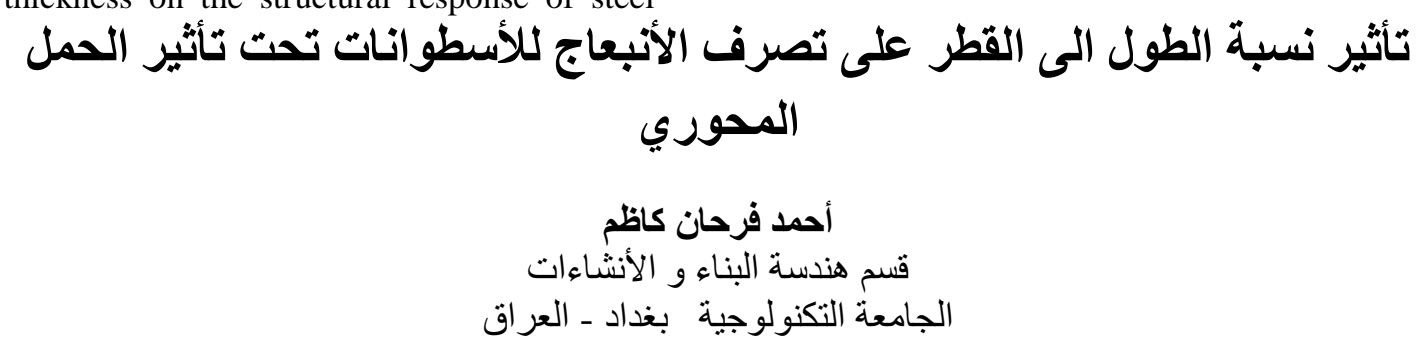

الخلاصة: في هذا البحث تم در اسة تصرف الأسطو انات القشرية تحت تأثثير الحمل المحوري. البرنامج العملي بتضمن مجمو عتين: المجمو عة الأولى تتكون من 9 أسطو انات، كل أسطو انة لها قطر (150 mm), بينما أرتفاع الأسطو انة

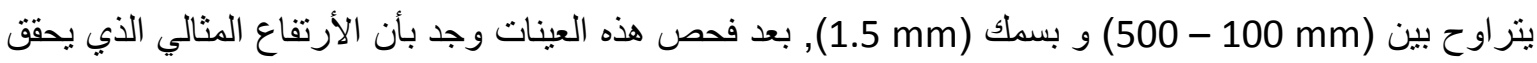

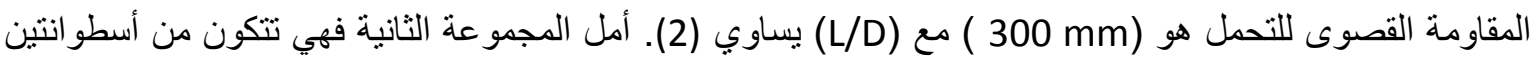

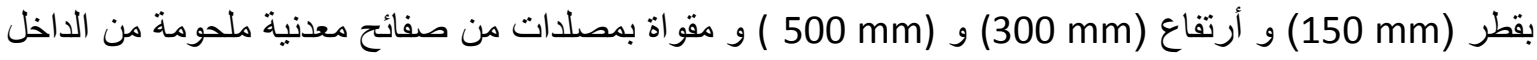

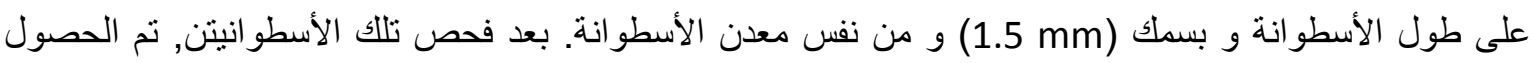

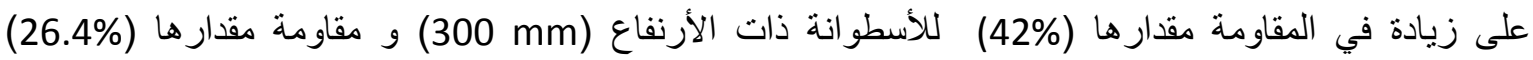
للأسطو انة ذات الأرتفاع (500mm) . أما شكل الفشل لتلك المجمو عتين فكان: الأنبعاج من الأسفل أخذا شكل "قدم الفيل" للأسطو انات ذات الأرتفاع (300 - 100 mm) و "الأنبعاج اللامرن" للأسطوانات ذات الأرتفاع ( - 500 ( 350 mm للمجمو عة الأولى, و "الأنبعاج اللامرن " للمجمو عة الثانية. 